\title{
The experiences of men engaged in transactional sex with other men in urban Nigeria-A size estimation and qualitative study
}

Population Council

Follow this and additional works at: https://knowledgecommons.popcouncil.org/departments_sbsr-hiv

Part of the Demography, Population, and Ecology Commons, Health Policy Commons, Health Services Research Commons, Immune System Diseases Commons, International Public Health Commons, Medicine and Health Commons, and the Virus Diseases Commons How does access to this work benefit you? Let us know!

\section{Recommended Citation}

"The experiences of men engaged in transactional sex with other men in urban Nigeria-A size estimation and qualitative study." Abuja: Population Council, 2012. 
THE EXPERIENCES OF MEN

ENGAGED IN TRANSACTIONAL SEX

WITH OTHER MEN IN URBAN

NIGERIA - A SIZE ESTIMATION

AND QUALITATIVE STUDY

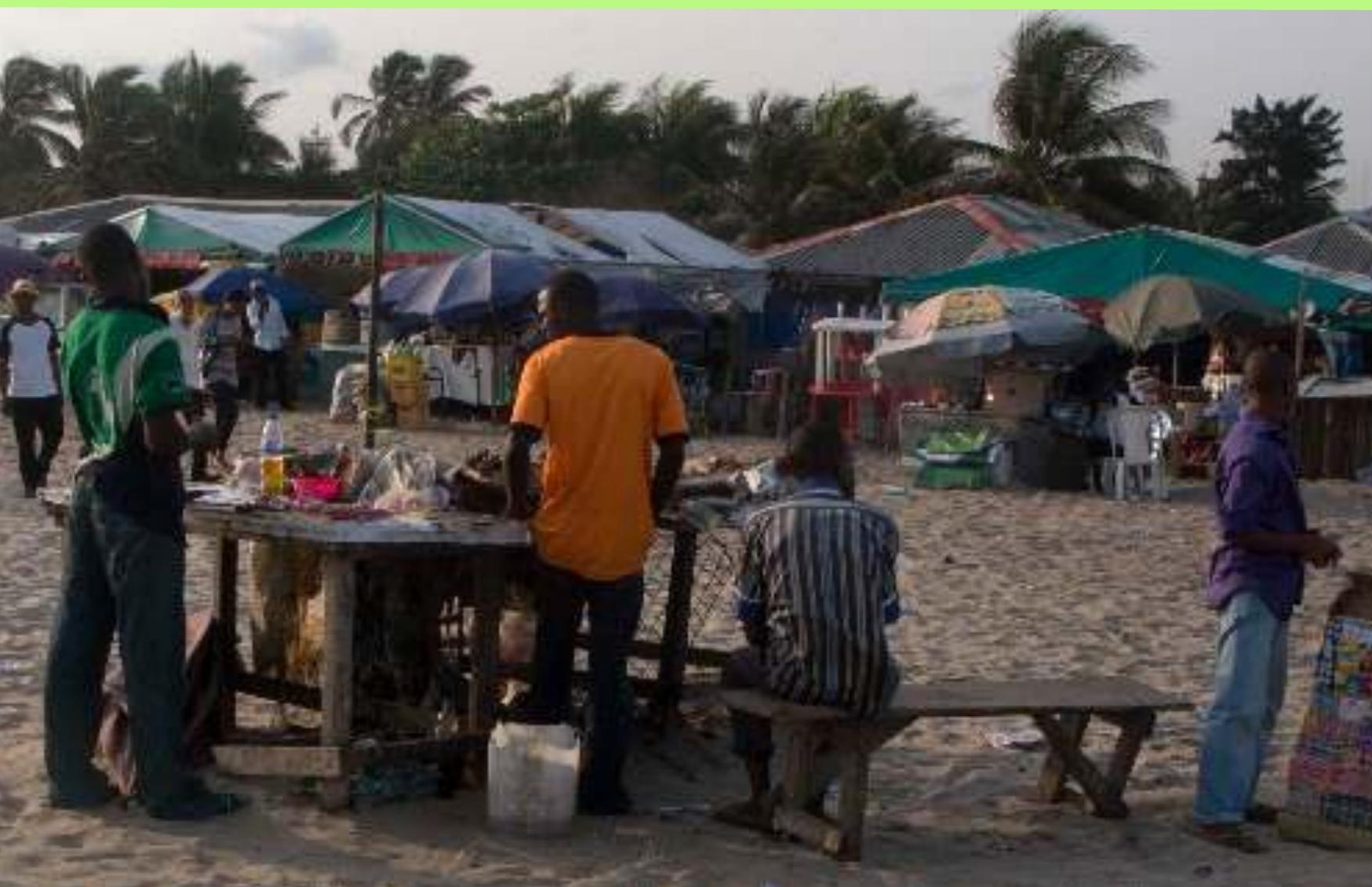

12 Population Council 


\section{(2) Population Council}

The Population Council confronts critical health and development issues-from stopping the spread of HIV to improving reproductive health and ensuring that young people lead full and productive lives. Through biomedical, social science, and public health research in 50 countries, we work with our partners to deliver solutions that lead to more effective policies, programs, and technologies that improve lives around the world. Established in 1952 and headquartered in New York, the Council is a nongovernmental, nonprofit organization governed by an international board of trustees.

This study was implemented by the Population Council, Nigeria with funding from the Ford Foundation.

The opinions expressed herein are those of the authors and do not necessarily reflect the views of the Ford Foundation.

For additional copies and information about this study please contact:

Population Council

Nigeria

16 Mafemi Crescent,

Off Solomon Lar Way,

Utako District,

Abuja,

Nigeria.

Tel: (+234) 9-870-6057; 806-778-6650

www.popcouncil.org 
Suggested citation: The Experiences of Men Engaged in Transactional Sex with Other Men in Urban Nigeria - A Size Estimation and Qualitative Study. 2012. Population Council Nigeria.

ISBN: $978-978-51172-3-3$

Any part of this publication may be photocopied without permission from the publisher provided that copies are distributed without charge and that full source citation is provided. The Population Council would appreciate receiving a copy of any materials in which the text is used.

Cover photo by Lucky Idedia (www.luckyosagie.wordpress.com)

(C) 2012 The Population Council, Inc 


\section{TABLE OF CONTENTS}

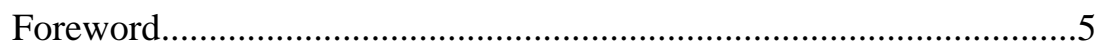

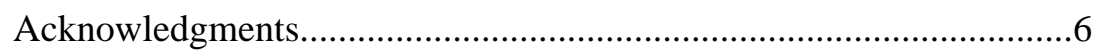

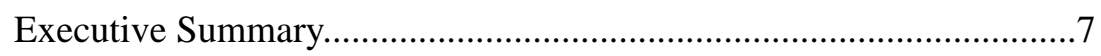

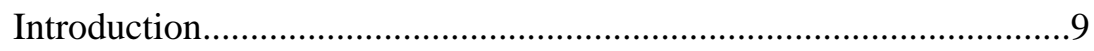

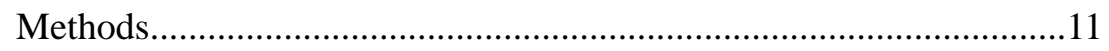

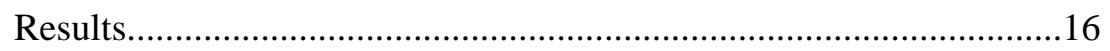

Implications and Recommendations....................................................40

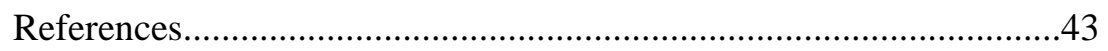

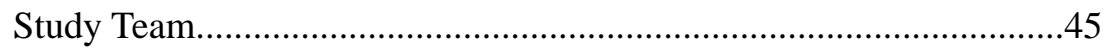




\section{FOREWORD}

The task of reducing new HIV infections in Nigeria behooves us to increase our knowledge and understanding of key drivers including those related to the most at risk populations (MARPs). Studies indicate that MARPs, including female sex workers (FSW), men who have sex with men (MSM) and injecting drug users (IDUs) constitute less than $1 \%$ of the general population but bear a higher burden of HIV infection. In 2010, MSM were estimated to account for about $9 \%$ of new infections in Nigeria ${ }^{1}$.

MSM sex workers constitute a higher risk group due to their double risk exposure and practice. Yet, few studies have documented the existence of MSM sex workers in Africa and much more is still unknown about the HIV burden among this sub-group of MSM. Furthermore, given the socioeconomic drive behind MSM sex workers, it is imperative to clearly understand risk behaviors and factors associated with their risk behaviors.

This is the first study in Nigeria to document the existence of MSM sex workers and to conduct the first size estimation of this group. It is our hope that it will serve as a useful reference guide for similar studies among this group and other MARPs in Nigeria going forward. More importantly, we hope this report will be a tool to help raise public awareness, to reduce stigma towards MSM and to stimulate interest in and action towards more targeted and tailored HIV prevention services for this group.

Adhiambo Odaga, DPhil, MFR

Representative for West Africa

Ford Foundation

Lagos, Nigeria.

${ }^{1}$ National Agency for the Control of AIDS. Modes of HIV Transmission in Nigeria, 2010. 


\section{ACKNOWLEDGMENTS}

This publication is based on research funded by the Ford Foundation and conducted by Population Council. Our team of interviewers were instrumental to the research process. Most especially, we thank the men who graciously gave their time and shared intimate details of their lives as participants in the research. This study is dedicated to them and to the goal of wellbeing for socially vulnerable sexual minorities in Nigeria and beyond. 


\section{EXECUTIVE SUMMARY}

Men who have sex with other men (MSM) have frequently been overlooked by initiatives to address sexual health in sub-Saharan Africa. Social stigma, denial that such men exist, and increased behavioural vulnerability have resulted in HIV prevalence rates for this group that are much higher than among the general population. In Nigeria, HIV prevalence among MSM has recently been estimated at $25.4 \%$ in Lagos and $11.7 \%$ in Kano-many times higher than the national adult prevalence estimate of $3.6 \%$.

The Population Council in Nigeria undertook a mixed-method research to estimate the population size and understand the experiences of a sub-group of MSM presumed to be at particularly high risk of infection with HIV and other STIs: men who engage in transactional sex with other men. After training local research teams and mapping locations where male-male transactional sex is commonly negotiated, we conducted an enumeration over two consecutive weekends in three Nigerian cities. We found that on an average weekend night an estimated 641 men in Kano, 865 in Lagos, and 358 in Port Harcourt were available to have sex with other men in exchange for money or gifts.

Follow-up qualitative research consisting of focus group discussions and indepth interviews were conducted in Kano and Lagos to provide a fuller account of the lives of men engaged in transactional sex with other men. We found that sex in exchange for money or other benefits is common among MSM in urban Nigeria, and that among the members of this community such transactions are considered a normal aspect of sexual relationships. Transactions are sometimes openly negotiated, but they are often merely expected, or made under the guise of paying for "transport fare". Those who provide sexual services are generally young men with unstable economic situations, while their paying partners are generally older and more financially established married men. Poverty and socio-economic inequality are the main reasons underlying such transactions.

Contacts for transactional sex between men are made and maintained in a variety of ways. Personal social networks and cell phones are commonly used to make connections while avoiding unwanted exposure and the security risks associated with anonymous encounters. Paid intermediaries are also 
sometimes used to facilitate encounters between male sex workers and their clients. Men also meet and negotiate paid sex with other men at private parties, bars and clubs, hotels, and other locations. Internet sites are increasingly popular for soliciting sexual partners, particularly in Lagos.

Most MSM live with the fear that their families or other people they know will discover that they have sex with other men. Verbal insults and physical attacks are committed against MSM, particularly against men who have more stereotypically feminine gender presentations. Thefts and blackmail are common occurrences, especially when sex workers and clients disagree over payment. However these crimes are infrequently reported to the police and several respondents stated that because of their sexuality, law enforcement or religious vigilante groups have harassed them.

MSM in Nigeria overwhelmingly have concurrent sexual relationships with female partners, or aspire to marry women in the future. Some desire relationships with women of their own accord, others want to marry for the sake of having children, while others marry because of family and societal pressure to do so. As such, MSM in Nigeria are not a closed sexual community, but rather are sexually integrated into the general population. The epidemiological implication of this is that because of the greatly increased prevalence of HIV among MSM, they constitute a bridge group to the general population.

MSM and especially those who have sex for money generally have high numbers of sexual partners, and sex workers tend to be the receptive partners in anal sex. In Lagos, self-reported condom use was relatively high and sexual health information and services for MSM are provided by a few nongovernmental organizations. However self-reported condom use and the awareness that unprotected anal sex constitutes a high risk of HIV infection were especially low in Kano. These facts are related to the lack of education campaigns and organizations addressing the sexual health of MSM. In both cities, most respondents said they were uncomfortable discussing same-sex sexual behaviours and anal manifestations of STIs with health care professionals. 
This study underscores the need for programs that specifically target sexual health messages and services to MSM in Nigeria and vulnerable subpopulations among this group. The findings indicate that policy responses and resource allocation for the development of appropriate interventions for MSM will have positive impacts not only for this group, but also for the health of the general population. However, the criminalization of consensual same-sex relationships at the federal and state levels hinders government agencies, international development partners, and civil society organizations from adequately addressing the pressing health needs of MSM and their partners. 


\section{INTRODUCTION}

Research on transactional sex in sub-Saharan Africa has traditionally focused on dynamics between women and men. Much of this literature has emphasized women as 'sex workers' or 'prostitutes', and men as their 'clients'. Over the past decade, scholarship has expanded to consider transactional dynamics that do not easily fit within the rubric of 'prostitution' (e.g. Cole 2009; Hunter 2002; Kaufman and Stravrou 2004; Masvawure 2010; Wojcicki 2002; Zulu et al 2004). These studies emphasize the entanglements of sexual affection and material support that exist in many African societies, particularly in contexts of worsening economic hardship and inequality.

African political and religious leaders have frequently asserted homosexuality to be "un-African" despite historical evidence to the contrary (e.g. Murray and Roscoe 1998; Epprecht 2008). Such assertions have been abetted by early public health depictions of the continent's AIDS crisis as 'Pattern II' (overwhelmingly or exclusively heterosexual), in contrast to the 'Pattern I' (overwhelmingly homosexual) epidemics seen in North America, Western Europe, Australia, and parts of Latin America. A growing body of epidemiological literature has nevertheless discovered not only that sex between men contributes to the African AIDS epidemics, but that MSM in cities across the continent have HIV prevalence rates many times higher than the general population (Griensven 2007).

In Nigeria, the Federal Ministry of Health's Integrated Bio-Behavioral Surveillance Survey in 2007 was the first attempt to estimate HIV prevalence for MSM. It found a prevalence rate for this population of $25.4 \%$ in Lagos and $11.7 \%$ in Kano-many times higher than the national adult prevalence estimate of 3.6\%. Focus group studies by Allman and colleagues (2007) and Family Health International (2009) found that networks of sexual minorities in Nigeria generally remain hidden, due to social stigma, family pressure, and criminalization.

The phenomenon of men transacting sex with other men has been considerably less studied than heterosexual exchanges, particularly in Africa. A few recent 
studies have explored the vulnerabilities of men engaged in transactional sex in African cities. Niang and colleagues (2003) found that men's sexual encounters in Dakar, Senegal were driven by a combination of love, pleasure, and economic exchange, and that high risk of HIV for these men was driven by unprotected anal intercourse and high rates of STIs. In Mombasa, Kenya, Geibel and colleagues (2008) found that 35\% of male sex workers were unaware that HIV could be transmitted by anal sex, and that this lack of awareness significantly predicted unprotected anal intercourse for this population. Arnott and Crago (2009) found that male sex workers in Botswana, Namibia, and South Africa faced considerable discrimination and criminalization.

Male-male transactional sex in Nigeria has been previously remarked, although rarely has it been a research topic in its own right. Moreover, the literature that does exist is heavily slanted towards northern Nigeria; the phenomenon has gone virtually unexplored in southern Nigeria. In an analysis covering 11 sub-Saharan African countries, Chatterji and colleagues (2004) found that young Nigerian men were substantially more likely to be engaged in transactional sex than older men, and that men from households with a low standard of living were significantly more likely to engage in transactional sex than men from high standard of living households. In a chapter on male bisexuality and the AIDS epidemic in Africa, Aina (1991) remarked that: "Apart from the male homosexual prostitution network that services what can be called an expatriate and tourist sector, there are also instances in Africa of an emerging predominantly indigenous sector. This is vividly illustrated by the northern Nigerian experience particularly in Kano, Kaduna, and some other cities. These men, although not as aggressive and obvious as the female heterosexual prostitutes, are available and identifiable by their styles and demeanor in the streets that constitute the red-light district of the Sabon-Gari area of Kano. Their clientele consists predominantly of wealthy members of the commercial, bureaucratic, and professional elites. The prostitutes have also developed an intricate system of bargaining and liason with their clientele. Apart from outright prostitution, the "sugar-daddy arrangement" is also used in male homosexual relationships in Nigeria (Aina 1991: 87). 
The most thorough study to address transactional sex among men is Gaudio's (2009) ethnography of 'yan daudu (feminine men) and other masu harka (men who have sex with men) among Hausa Muslims in Kano. Some 'yan daudu spend time working in gidajen mata ('women's houses', also often translated as 'brothels'). Gaudio analyses these activities in terms of karuwance ('courtesanship'), rather than as 'prostitution' as it is understood in contemporary Western societies. In other words, yan daudu and female karuwai ('independent women') "provide a number of services other than sex: they serve food and drink, play cards and board games, and engage their visitors in friendly, flirtatious conversation" (p.6). Pittin's (2003) account of karuwai in late 20th century Katsina city also makes repeated reference to 'yan daudu's work in 'women's houses' in northern Nigeria, sexual and otherwise. Kleis and Abdullahi (1983) were the first researchers to write about the exchange of sex for money and other gifts between 'yan daudu and more conventionally masculine men in Kano. These studies suggest that transactional sex among men in Nigeria may have a longer history than is typically imagined.

There has been growing recognition that male-to-male sexual transmission contributes disproportionately to Nigeria's HIV/AIDS epidemic, and that MSM have been substantially underserved with sexual health programs. Moreover, it has long been recognized that sex work and other forms of transactional sex put individuals at heightened risk of infection and associated stigmas. To our knowledge, this study is the first to estimate the number of men who sell sex to other men in Nigeria. It is also the first study that uses qualitative methods to focus specifically on the experiences of men engaged in transactional sex with other men in the country. 


\section{METHODS}

\section{Enumeration of men providing sexual services to men in Kano, Lagos, and Port Harcourt}

'Capture-recapture' is a method for estimating the prevalence of a trait in a population. Initially used in research on populations of wild animals which were captured, marked, released, and recaptured, the same statistical process is now used to estimate other types of populations. The basic idea of capturerecapture studies is to sample and identify individuals, or cases, from a population and then resample the population to see what fraction of individuals, or cases, in the second sample were identified in the first sample (i.e. the fraction of individuals, or cases, that were found in both samples). This method has also been found useful in estimating the sizes of hard-to-reach and stigmatized human populations. In this case, and following a model used by Geibel and colleagues in Kenya (2007), the capture-recapture method was used to estimate the number of men willing to have sex with other men in exchange for money or other gifts in Kano, Lagos, and Port Harcourt.

We first conducted informal interviews with key informants and mapped locations where men meet other men to arrange transactional sex. These "hotspots" included bars and clubs, shopping areas, cinemas, beaches, and private residences. We also determined the popular meeting times at these locations, and made contacts with necessary "gatekeepers" to inform them of our study. The preliminary qualitative assessment furthermore explored the social organization of transactional sex, including how verbal and body language was used to indicate intent to engage in transactional sex.

In each of the three cities where the research was conducted, a team of local male researchers were trained to carry out the enumeration. These trainings took place at week-long participatory workshops. The trainings encompassed both theoretical as well as practical sessions in carrying out qualitative research, quantitative surveys, dealing with sensitive/taboo subjects, confidentiality, ethics, fieldwork procedures, form completion, safety, and public health promotion.

In each city the enumeration involved conducting two "counts". The first count ("capture") contacted men engaged in transactional sex with other men and "tagged" them. The second count ("recapture", conducted one week later) counted the men who were "tagged" the previous week, as well as newly 
encountered men. Enumerators were divided into teams and assigned to the locations identified during formative research and mapping, where they employed a three-step approach to identify MSM sex workers/informants:

1) Identification of MSM sex workers through body language and other techniques identified during formative research and participatory research planning;

2) Interaction with these informants and their self-identification as MSM; and

3) Confirmation that the informant is attempting to sell sex to other men.

Enumerators first visually identified individuals thought to be MSM sex workers, then discreetly approached and started casual conversation with a suspected contact (i.e., informant). Once the enumerator was confident of the contact's status, the enumerator asked in the socially appropriate context if the MSM was seeking clients for sex in return for money, drugs, etc. If the above conditions were met, a "tag" will was given to the informant in the form of a unique key chain produced specifically for the study. In offering the "tag", the enumerator confirmed that the informant was indeed an MSM sex worker. The informant was free to either accept or refuse the key chain, but in either circumstance, the enumerator kept a record of the event cataloguing the time, date, and location of each identified informant.

If the identified MSM sex worker accepted the key chain, they were considered a "capture". If another enumerator approached the informant at another time or place on the same night, they first asked if the informant had received the key chain from anyone else that night. If they replied 'yes', the contact ended there. The enumerator then approached next potential informant and repeated the process.

The initial steps of the "recapture" were the same as the "capture". The enumerators observed behaviour in the assigned location, approached men suspected of soliciting sex, confirmed their status, and then offered a second unique key chain. However, for the recapture several more questions were asked:

- Was the informant offered a keychain (tag) previous week, and from whom;

- Did the informant accept the key chain in the previous week; 
- Did the informant receive a key chain this week, and if yes from whom;

- Did the informant accept a key chain this week?

A formula was then used to calculate the estimated population size.

- $\quad \mathrm{c} 1=\mathrm{MSW}$ captured in first count

- $\quad$ c2=MSW captured in second count

- $\mathrm{m}=$ Matches (MSW captured in both counts)

- $\mathrm{n}=$ Estimated population size

Where: $\quad 95 \%$ CI $=n \pm 1.96 * \sqrt{\operatorname{Var}(n)}$

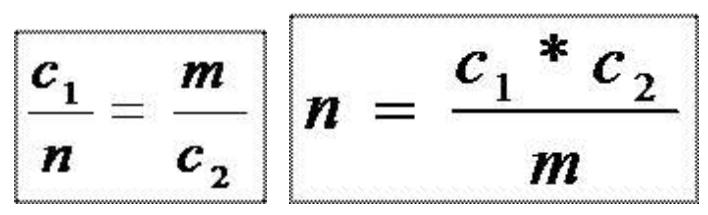

$$
\operatorname{Var}(n)=\frac{c_{1}^{*} c_{2} *\left(c_{1}-m\right) *\left(c_{2}-m\right)}{m^{3}}
$$

There are several limitations to the capture-recapture method in estimating the number of men transacting sex for money or gifts. First, location-based solicitations comprise only a portion of male-male sex work activity. Enumerators, sex workers, and other MSM we spoke with said that most male sex workers in this era of mobile phones work as "call boys", whereby clients call them (or call an intermediary) to arrange a meeting. Such encounters would thereby be missed by the capture-recapture methodology. Moreover, internet-facilitated meetings on gay chat sites are increasingly common, especially in Lagos and Port Harcourt.

A second limitation is that with around 30 enumerators in each city and the need for enumerators to work in pairs given security concerns, the terrain that we were able to cover was necessarily limited. The number of sex workers enumerated is at least in part a function of the number of enumerators working - and moreover the relative competency and dedication of the enumerators. 
A third methodological limitation is that research was conducted on only one day of the week: two consecutive Saturdays in Kano, two consecutive Fridays in Lagos, and two consecutive Saturdays in Port Harcourt. Therefore, locations that were "hot" for male sex work on other days of the week could not be counted. (For example, the National Theatre in Lagos on Sunday evenings is considered the single most concentrated time and location for male sex work in the city-but on Friday night our enumerators did not have a single "capture" there.)

\section{B. In-depth interviews with MSM engaged in transactional sex}

In-depth qualitative interviews were conducted with 21 respondents in Kano and 23 respondents in Lagos. A semi-structured interview guide was developed to cover various domains of experience, including characteristics of men engaged in transactional sex with other men, reasons for engaging in transactional sex, negotiations, stigma and secrecy, family life, alcohol and other drug use, knowledge and behaviours surrounding sexual health, and access to health services. This interview guide and informed consent documents were also translated into Hausa.

Personal networks and snowball sampling were used to recruit the interview respondents. The majority of participants recruited for the interviews were men who "sold" sex to other men or worked as intermediaries (i.e., "pimps"), but some men who paid for sex were also interviewed. In each city, several key informants who worked with health and advocacy organizations were also recruited for interviews to provide a broader context. All respondents were 18 years or older. A team of six experienced male qualitative interviewers were trained during a three-day participatory meeting.

One-on-one interviews were scheduled and conducted in a safe and private location following informed consent procedures. Each interview lasted approximately one hour, and was digitally recorded. Respondents were remunerated to cover the costs of travel to and from the interview. The interview recordings were then transcribed, translated (in the case of the interviews conducted in Hausa), and coded for qualitative analysis. 
Two limitations were evident in these interviews. There was the potential for responses reflecting social desirability bias: respondents may have a tendency to exclude or change certain details about experiences that are embarrassing, illegal, or otherwise put themselves in an unflattering light. To minimize this, interviewers stressed that all responses would be kept confidential and anonymous, and were trained to interact with respondents in a friendly, nonjudgmental manner. Interviewers were also trained in open-ended questioning techniques. (For example, rather than asking respondents, "Do you use condoms?" interviewers would attempt to elicit stories from respondents about their experiences using or not using condoms with different sexual partners.)

A second limitation involved the demographic characteristics of the interview respondents. Our oldest respondent was only 42 years old, and a large majority of the respondents were in the 20s. There was thus a bias towards younger respondents. Furthermore only a very few of our respondents could be considered from the upper socio-economic class, as despite our efforts it was much more difficult to get older and professional men to openly discuss their participation in illegal and stigmatized activities such as homosexuality and transactional sex.

\section{Focus group discussions with men engaged in transactional sex}

Additionally, two focus group discussions were conducted in Kano, and two in Lagos. Each had between six and eight participants. A focus group discussion guide was developed to cover various domains of experience, focusing on group norms and perceptions. This guide along with informed consent documents were translated into Hausa for use in Kano. Respondents were recruited in a similar manner as with in-depth interview respondents, and paid to cover their transport costs. Following informed consent procedures, a trained focus group discussion leader conducted the focus groups. Each group lasted approximately two-and-a-half hours. 
A limitation of focus group settings is that respondents may not feel comfortable discussing intimate details about their lives in a group, especially in tight-knit communities of MSM where there is concern about gossip. We attempted to minimize this by stressing the importance of confidentiality and not repeating details of the discussion afterwards. And as with the in-depth interviews, the focus groups were biased towards younger men, with the large majority of participants in their 20s. 


\section{RESULTS}

A. Population estimate of men providing sexual services to men in Lagos, Kano, and Port Harcourt

Preliminary key informant interviews with MSM including sex workers, clients, and their intermediaries yielded lists of dozens of "hotspots" in each of the 3 study cities where men seeking paying male sex partners congregate. These locations were coded in 7 broad categories:

\begin{tabular}{|l|l|l|l|}
\hline & Kano & Lagos & Port Harcourt \\
\hline Private homes & 6 & 10 & 2 \\
\hline Streets/ public areas & 29 & 8 & 7 \\
\hline Cinemas & 4 & - & - \\
\hline Shopping areas & 6 & 4 & - \\
\hline Eateries & 4 & 4 & 4 \\
\hline Clubs/Bars & - & 9 & 23 \\
\hline Hotels/ pools & 7 & 3 & 6 \\
\hline Total & 56 & 38 & 42 \\
\hline
\end{tabular}

The locations were then mapped and geographically sub-grouped for proximity. In each city, a local team of 30 enumerators was assembled and trained. The enumerators were then divided into teams and assigned to work in pre-determined locations and at specific times to conduct the research. In Kano, research was conducted on the evenings of $25 \mathrm{~J}$ uly and 1 August 2009. The results were as follows:

\begin{tabular}{|c|c|c|c|c|c|c|c|}
\hline \multirow[b]{2}{*}{ KANO } & \multicolumn{3}{|c|}{ FIRST COUNT (25 July 2009) } & \multicolumn{4}{|c|}{ SECOND COUNT (1 August 2009) } \\
\hline & $\begin{array}{l}\text { ACCEPT } \\
\text { TAG }\end{array}$ & $\begin{array}{l}\text { REFUSE } \\
\text { TAG }\end{array}$ & $\begin{array}{l}\text { ALREADY } \\
\text { COUNT }\end{array}$ & $\begin{array}{l}\text { NEW } \\
\text { CAP }\end{array}$ & RECAP & \begin{tabular}{|l|} 
REFUSE \\
TAG
\end{tabular} & $\begin{array}{l}\text { ALREADY } \\
\text { COUNT }\end{array}$ \\
\hline TOTAL & 289 & 33 & 11 & 149 & 122 & 25 & 19 \\
\hline PRIVATE HOMES & 22 & 3 & - & 9 & 26 & 2 & - \\
\hline CINEMAS & 38 & 5 & - & 15 & 3 & 1 & 1 \\
\hline STREETS/ PUBLIC AREAS & 163 & 17 & 5 & 98 & 66 & 20 & 10 \\
\hline SHOPPING AREAS & 18 & - & - & 9 & 3 & - & 2 \\
\hline CAFE/BAR/RESTAURANTS & 15 & 5 & 6 & 12 & 10 & 1 & 6 \\
\hline HOTELS & 33 & 3 & - & 6 & 14 & 1 & - \\
\hline
\end{tabular}


In Lagos, research was conducted on the evenings of 7 August and 14 August 2009. The results were as follows:

\begin{tabular}{|c|c|c|c|c|c|c|c|}
\hline \multirow[b]{2}{*}{ LAGOS } & \multicolumn{3}{|c|}{ FIRST COUNT (7 August 2009) } & \multicolumn{4}{|c|}{ SECOND COUNT (14 August 2009) } \\
\hline & $\begin{array}{l}\text { ACCEPT } \\
\text { TAG }\end{array}$ & $\begin{array}{l}\text { REFUSE } \\
\text { TAG }\end{array}$ & $\begin{array}{l}\text { ALREADY } \\
\text { COUNT }\end{array}$ & $\begin{array}{l}\text { NEW } \\
\text { CAP }\end{array}$ & RECAP & $\begin{array}{l}\text { REFUSE } \\
\text { TAG }\end{array}$ & $\begin{array}{l}\text { ALREADY } \\
\text { COUNT }\end{array}$ \\
\hline TOTAL & 245 & 20 & 4 & 157 & 62 & 13 & 7 \\
\hline PRIVATE HOMES & 34 & - & - & 10 & 8 & 1 & - \\
\hline HOTELS & 36 & 3 & - & 19 & 19 & - & - \\
\hline CLUBS & 43 & 3 & 1 & 15 & 3 & - & - \\
\hline BARS & 10 & - & - & 30 & 14 & 1 & 2 \\
\hline STREETS/ PUBLIC AREAS & 40 & 6 & - & 31 & 8 & 1 & 1 \\
\hline SHOPPING MALLS & 82 & 8 & 3 & 52 & 10 & 10 & 2 \\
\hline
\end{tabular}

In Port Harcourt, research was conducted on the evenings of 12 December and 19 December 2009. The results were as follows:

\begin{tabular}{|l|l|l|l|l|l|l|l|}
\hline \multirow{2}{*}{ PORT HARCOURT } & \multicolumn{6}{l|}{ FIRST COUNT (12 December 2009) } & \multicolumn{2}{l|}{ SECOND COUNT (19 December 2009) } \\
\cline { 2 - 9 } & $\begin{array}{l}\text { ACCEPT } \\
\text { TAG }\end{array}$ & $\begin{array}{l}\text { REFUSE } \\
\text { TAG }\end{array}$ & $\begin{array}{l}\text { ALREADY } \\
\text { COUNT }\end{array}$ & $\begin{array}{l}\text { NEW } \\
\text { CAP }\end{array}$ & RECAP & $\begin{array}{l}\text { REFUSE } \\
\text { TAG }\end{array}$ & $\begin{array}{l}\text { ALREADY } \\
\text { COUNT }\end{array}$ \\
\hline TOTAL & 211 & 63 & 3 & 209 & 61 & 33 & 15 \\
\hline HOTELS/ POOLS & 22 & 3 & 2 & 31 & 4 & 3 & - \\
\hline DANCE CLUBS/BARS & 121 & 54 & 1 & 88 & 34 & 21 & 9 \\
\hline EATERIES & 15 & 4 & - & 20 & 2 & 3 & 4 \\
\hline PRIVATE HOMES & 13 & 2 & - & 48 & 7 & 6 & 2 \\
\hline STREETS/ PUBLIC AREAS & 40 & - & - & 22 & 14 & - & - \\
\hline
\end{tabular}

Using the formula explained in the methods section above, we therefore estimated that on any given weekend night, 353 men in Kano $(95 \% \mathrm{Cl}$ : 332-373), 620 in Lagos (95\% Cl: 517-724), and 723 in Port Harcourt (95\% Cl: 594-892) are willing to provide sex to other men in exchange for money or goods. 
The enumerations were limited to men that we were able to encounter in predetermined locations, and therefore did not address those using technologies such as cell phones or the internet to meet paying clients. As the follow-up qualitative research described below demonstrates, connections for transactional sex made through social networks using cell phones and the internet or at occasional parties are even more common than location-bound encounters. Therefore, the estimates from the 'capture-recapture' exercise likely understate the actual number of men willing to provide sex to other men in exchange for money or goods.

\section{B. Identities and terminologies}

Gaudio's (2009) research on 'yan daudu-Hausa men who are said to speak and behave in stereotypically feminine ways and have sex with other men-demonstrates that a well-developed "harka dialect" exists among Hausa-speaking MSM. Research by Family Health International (2009) has documented the similarly rich in-group slangs used among English-speaking MSM in Lagos and Abuja. Our study similarly found that a great many terms are used by MSM in Nigeria to describe sexual identities, behaviours, and transactional sex between men. While certain of these terms are common among MSM throughout Nigeria, many are specific to particular locations and languages. Such terms are often euphemistic and used by MSM specifically to avoid detection by outsiders.

The following list is not a comprehensive glossary of such terms and their meanings. Instead, we highlight some of the identities and terms that are most commonly used and most directly related to transactional sex among men. Because our interviews and focus groups were conducted in English and Hausa most of the terms listed are from these two languages, but several Yoruba terms commonly used in Lagos are also included.

LAGOS (or among English speakers more generally)

Market: Transactional sex. For instance, to be 'on market' is to be looking to get paid for sex. 'Your market is selling' means that one is attracting sexual partners. 
Runs: 1) The act of having sex to get paid, as in 'doing runs'.

2) Paying sex partners. For example, 'I need runs' can mean 'I need clients'.

Ashawo: Yoruba for 'prostitute'. Usually used to refer to women, but also used among MSM to refer to male sex workers.

Omo oloja: Yoruba for 'market child'; slang for 'sex worker'.

White hunter: Male sex worker who goes after foreign (especially white) clients.

Scrobos: Sexual partners, often implying paying clients.

Angolo: A white man (for instance, one who is a paying sex partner)

Beta: A well-paying client

Aristo: An older married or rich client (from 'aristocrat')

Daddy: An older male sex partner, especially one who pays for sex

Call-boy: Younger man who has sex for money or gifts and is connected to clients via his cell phone

Chewing-gum boy: A financially unstable adolescent who depends on male clients for money or gifts. Somewhat derogatory.

Converted: Straight-identified-or formerly straight-identified-man who has sex with other men, especially for money

Agent: An intermediary between sex worker and client, i.e. a 'pimp'

Knock-out: To steal, especially from a sex partner. A 'knock-out girl' is a MSM who steals.

Rice/top/king: Masculine or anally insertive sexual partner

Beans/bottom/queen: Feminine or anally receptive sexual partner

Sagba: Homosexual (from Yoruba) 
Tibi: Homosexual (shorthand for 'T-B', or 'top-bottom', i.e. the insertive and receptive roles in anal sex.

Laptop: 1) Interfemoral sex (i.e. 'thigh sex'). 'We did laptop' means 'we had thigh sex'. 2) Also used as an identity term for someone who penetrates men between the thighs but not anally.

Packing: Anal sex. 'I got packed' means 'I got penetrated'. 'I packed him' means 'I penetrated him.'

Garnish: Anal sex.

Maggi: Lubricant for anal sex or thigh sex

\section{KANO}

Harka: In-group term among MSM for 'gay sex', especially anal sex. In standard Hausa,'harka' means 'business'.

'Mai harka' is a man who has sex with other men (plural: masu harka)

Karuwanci: General Hausa term for 'prostitution', but also used for male sex work.

Karuwa: Generally a female prostitute, but also used for male sex workers (plural: karuwai)

Mai ido: Someone who does harka. (Literally, 'a person with eyes'.) 'Yana da ido' means 'He has sex with men', (literally, 'He has eyes')

Mai ido daya/Mai rabin ido: Someone who is aware of and friendly with masu harka but who does not himself do harka. (Literally: 'one-eyed person'/'halfeyed person)

Maras ido: A straight person (Literally, 'a person without eyes'). Also used are makaho (literally, 'blind man') and akwuya (literally, 'goat')

'Dan luwadi/'Dan homo: Homosexual. Somewhat derogatory when used by non-MSM.

'Dan daudu/'Dan hamsin: A man who behaves like a woman; often presumed 
to do sex work. Somewhat derogatory.

Me'ka: More preferred in-group term for effeminate man, and less well known by general public. [Plural: me'koki]

'Dan siddan: A younger male sex partner who is more stereotypically masculine than me'ka, often presumed to have sex with men for money.

'Dan snooker: Young and stereotypically masculine men who are presumed to have sex with men for money. So-called because they hang out on streets and play at snooker tables.

Mare-ni: A young boy who has been forced to admit that he has sex with other men, akin to the American English slang 'jail bait' (literally, 'slap me')

Tarkon alkali: Another term for a young boy who has been forced to admit he has sex with men (literally, 'judge's trap')

'Dan aras: A masculine and generally older male sexual partner [Plural: 'yan aras]

Hajiyar sama: Insertive partner in anal sex, i.e. 'top'

Hajiyar kasa: Receptive partner in anal sex, i.e. 'bottom'

Kwazo: A masculine and generally older male sexual partner

Kawali: An intermediary between prostitute and client. A general Hausa term, but also used among MSM.

Ajo: A party held by mekoki to obtain money and gifts from their sexual partners

Baya: Anal sex (General Hausa word meaning 'behind' or 'backside')

Birni: Anal sex; anus. (Literally: 'city')

Lemu: Penis (Literally: 'soft drink')

'Kauye: Thigh sex; thighs. (Literally: 'outside the city'; 'rural area') 
Garwa: 1) A straight person who doesn't know about gay sex.

2) To expose someone for engaging in same-sex sex (Literally: 'tin can', from the loud noise made from banging on a tin can)

\section{Characteristics of men engaged in transactional sex}

Men involved in transactional sex in Nigeria come from all ethnic groups and social classes. Paying clients tend to be married and relatively more financially secure, whereas those being paid tend to be unmarried and financially insecure. Secondary and university students and other unemployed or underemployed men are those most likely to have sex for money:

My clients are mostly business people and working-class guys. Age bracket should be 29 upwards. They should be working or doing something to earn a living. I was doing it then because I was in school, just to make ends meet. (Kano interview respondent)

Moreover, categories of "client" and "sex worker" are not entirely fixed. Some men both get paid for sex and pay for sex, depending on who their sex partner is:

Me I collect money o, though some people say it's transport. If I see a young boy I love too, I give him money, though if I meet married men, I get money from them too. (Lagos interview respondent)

It depends on who is more financially capable. If I am the one with the upper hand, it behoves me to support him financially like giving him transport fare, money to feed himself, and stuffs like that. (Lagos interview respondent)

At times I give them money because they will always ask for transport, and I love men between the ages of 18 and 25 years. But if I have sex with white men, I make sure I collect money from them. Not that I ask them to pay me, because I see that as foreign aid [Laughs] (Lagos interview respondent)

Most men engaging in transactional sex view themselves as naturally 
homosexual or bisexual:

I like men. I'm not interested in women. That is how God made me. (Kano interview respondent)

But several men who collected money for sex with other men identify themselves as straight but "converted" to sex with other men. Among MSM it is commonly believed that many straight-identified men can be "converted" for money:

I consider myself straight [Interviewer: Why?] Why? Because I don't act like others that I do see. Maybe others, when you just see them will say, 'This one is a gay.' Maybe his steps. Some do chew gums around. I'm not into all that thing. (Kano interview respondent)

In Lagos there is this saying or feeling that gay men are rich and generous, and that if you can satisfy them sexually, they can help you in many ways. So the so-called straight guys now say they can have sex with men as long as money is involved. So the pimps have friends they have spoken with, and they are like, 'Guy, just go sleep with these guys and fuck him, at least you're not being fucked.' And they feel comfortable with it, and as long as the money is going in. (Lagos interview respondent)

Some men who are paid for sex insist that most of their paying sex partners were straight identified:

Some straights will just like you and walk to you, maybe they love your dressing and they will be like, 'How do you do it?' Some will ask to sleep with you. (Lagos focus group respondent)

\section{Reasons for transactional sex}

In his chapter published twenty years ago, Aina stated that "male homosexual prostitutes interviewed in Kano and Lagos in Nigeria still believe that there are magical and witchcraft effects associated with male homosexual intercourse. 
They also believe that if the dominant partner is a business man, such associations confer spiritual benefits to his business" (1991, p.88). It is notable that none of our participants reported similar beliefs in magical or witchcraft effects associated with their transactional same-sex relationships. Instead, those who provided sexual services generally foregrounded economic motivations. These respondents emphasized transactional sex as an informal economic strategy.

Many men are introduced into transactional sex in adolescence, often by an older friend or authority figure:

I didn't even know such [getting paid for sex] existed, until I later got mentored by another guy who taught me how to charge good money. I started making close to 1,000 naira [per sexual encounter] in secondary school. (Lagos interview respondent)

For most people it started from secondary school, like they have this school father who protects them from punishment, from other seniors, gives provisions and all. For me, that's transactional sex right there, because something is being exchanged for sex - though they may think they are just favoured. And then later I think they get to a point where they are broke and don't want to steal or commit crime, and then it's like, 'What's the fastest way of making money?' And then somebody asks that they hook up, and after telling the person they will be needing transportation fare they are given huge sums of money far above the fares. And they are like, 'Wow! Good deal!' (Lagos interview respondent)

Sports coaches are frequently noted to be first transactional sex partners:

Like some boys that play football, you'll see some of the older guys buying them shoes and things. When you need money, they'll give it to you gradually. And you'll be surprised: 'Why are these men giving me these things?' Then you'll see that one day they will come to you looking for sex. And you won't say no to them, because of what they've been giving you or the money. You won't refuse to give them the sex they want. And that is the way you get yourself into it.' (Kano focus group respondent) 
You know as a [football] coach, we can go around and say, 'You, you, you no have foot wears, socks.' Then we now dash him because of poverty. Anything you say they should do, they will do it. [...] Like one of the boys call me and says, 'Oga sir, I no have hand glove', and that one is a [goal] keeper. Like they know I am selling it, and some may say, 'Please, my money have not reach. Take half.' Then I say, 'Forget the rest.' (Kano interview respondent)

I was pressured by the coach of my football team until he had his way. So I was really scared and feeling scared until I got enlightened because I was never in the knowledge that money could be paid for sex until 3 years ago. (Lagos focus group respondent)

Poverty, social inequality, and lack of regular employment are the main factors underlying most male-male transactional sex in Nigeria:

I was fighting to survive. I'm the only child in our house, and I struggle to help my family. There were a lot of times when I had no money; I would go to other guys to fuck me. Now I know a lot of people that I get money from by having sex with them. Otherwise, I am jobless. (Kano interview respondent)

I had no money at all. I was told about a guy who will give you money if he has sex with you. So I asked about his address, got the address and went his residence. When I got to his house, there were other guests who came to him. So I returned back the next day, and he fucked me and he gave me 5000 naira. So I managed that money to sustain myself for some days, and when the money was finished I would go to other guys to have sex. And through them I now know a lot of others. (Kano interview respondent)

Honestly speaking, I could say poverty is the main reason for harka. Our leaders keep us in artificial poverty. You will see a boy hawking pure water at a junction, and if you try having sex with him you'll realize that he is already doing it as a result of the sullen poverty he encounters in his life. (Kano interview respondent)

My friends have finished [National Youth] service. They are now in Lagos. What are they doing? Prostitution - to earn a living, because jobs are not 
forthcoming. (Kano interview respondent)

But not all men selling sex are facing destitute poverty. Some use sex work to supplement their other steady sources of income. For such men, transactional sex becomes a sort of second job:

Even some of us that are self-employed still engage in transactional sex work either through pimping, trafficking or the sex work itself. Owo o ki n to olowo ('Money is never enough for the rich man') because we still always need money. (Lagos focus group respondent)

If I have a date with a man, you must give me money. [Interviewer: So how do you combine it [with your day job]? I tell them that from a time, like 6pm, I'll be free when I have closed work to catch fun. (Lagos interview respondent)

The economic situation is not that good, so people tend to do several things to make ends meet. Plus if you're now the bread winner of your family and you're working at a place where they just pay you, say, 20,000 naira a month, you want to do other stuffs. But for me sex is fun-but if you want to enjoy yourself and get paid for it. Because some of them do it in the evening, because the guys who also want sex usually want sex at close of business. So I think it's a better deal than going out all day and not having anything to show for it. (Lagos interview respondent)

Among MSM in Nigeria, there is little stigma surrounding engagement in transactional sex, either as a "worker" or "client". Whether or not it's thought of as "sex work", most men expect that sex will come with either giving or receiving some form of financial benefit:

[Interviewer: In all the times men have sex with men in Lagos, what's the percentage of times money is exchanged?] I will say 97.3 percent. Reason, because at every stage, something is exchanged for something. And yeah, I have been in the community for a while so for every sexual activity I have been involved in, something has exchanged hands. And it could be clothes, shoes, phones. It's just a few times it's been, 'Ok, let's have fun and we each go our separate ways.' (Lagos interview respondent) 
To add to that, you know, Others, first move back and they are like, 'Why are you doing runs if you are a real gay?', but when they see you with Louis Vuitton or Givenchy bags today and with Gucci tomorrow, say you're making shit out of shit, they are like, 'My friend, teach me now'. They spring back to try learning how you do stuff. Like I was a bit sceptical when I first heard about it but now I do it, and that my friend who taught me is my mentor. (Lagos focus group respondent)

Several men feel that transactional sex is considered normal among MSM because it is relatively common and acceptable in Nigerian society more generally:

If you take somebody out and have sex with him, you have to show him that you enjoy it by giving him something. At least you show him some appreciation. It's just like with women: you can't just have sex with a girl without spending some money. (Kano interview respondent)

It goes beyond MSMs, because the community we live in generally accepts it. Say we have a sister who doesn't sleep home but she is living large, she is dropped by different big cars and all we know is that she has a lot of money, it doesn't mean anything again. It's no big deal maybe because the economy is very weak. (Lagos focus group respondent)

\section{E. Social spaces}

Aina's assertion that male "prostitutes can be found in virtually all large African cities and tourist centers, around the five-star and other hotels catering mainly to an expatriate clientele and the local rich" (1991, p.86) was true for the three cities in which we conducted our research--but these were far from the only types of venues where men were soliciting for and engaging in transactional sex with other men. Instead we found that men meet other men for sex in a wide range of spaces, both physical and virtual (e.g. online).

In both Kano and Lagos, men meet each other for transactional sex in a wide range of locations. Sometimes these are the types of places where female sex workers are also concentrated, such as bars, clubs, hotels, and on certain 
streets. Private gay parties and private homes (which are sometimes de facto brothels) are also common meeting places, as are certain beaches in Lagos. But men also meet and transact sex in more prosaic public locations:

Like the white guys, I meet them over the internet or through friends. And for the Nigerian guys, anywhere: on the street, the internet, market, at times in churches, schools, burger joints, filling stations-just name it. (Lagos interview respondent)

Sometimes we meet on the street. Somebody will see you and want to take you out. If you are doing it, you will follow him. If you don't do harka then you tell him, 'I don't do it.' That's all. (Kano interview respondent)

As one respondent explained, wealthier men who want to have sex are better able to avoid the reputational risks of being seen in the sorts of places where sex workers congregate:

Both rich and poor men pay money [for gay sex], but rich guys have boys brought to them more often, whereas poor people go to joints and pick them up themselves. (Kano interview respondent)

Some Nigerian men travel internationally to meet paying male sex partners. Men in Lagos cited trips to nearby costal West African countries; whereas men in Kano said that they engage in transactional sex in Saudi Arabia:

We go to Togo, to Ghana, and take people there and get paid for it after due and clear negotiations. So I organise guys too, after money is paid into my account. (Lagos interview respondent)

Men do harka in Mecca more than any other place. I have a cassette videotaped in Jeddah where such things happened. Sometimes, you will be approached by them [Saudi men] while walking or on your way home. (Kano focus group respondent)

Whenever me'koki travel to Mecca, everybody knows what you will go there to do. (Kano focus group respondent) 


\section{F. Technology and social networking}

Given the security risks inherent in making anonymous same-sex sexual contacts in public locations and the potential for misinterpreting an unknown man's availability, men in Nigeria generally prefer to be connected to new partners through friends and acquaintances:

Some of the guys who I met in Lagos through that my church guy, he will link me up with other guys, and those guys will link me with other guys in my school, and outside through phone call, and I will go and meet them after our communication. Like in school, I had plenty fun o. Somebody could call and say, 'Guy, a guy just landed in town', and I will say, 'Let me pick a bike and I will go there and spend a night.' (Lagos interview respondent)

It is difficult to understate the importance of cell phones in men's same-sex connections. As wireless usage has expanded in urban Nigeria over the last ten years, the relative ease and safety of making contacts through this medium has made it the method of choice for MSM in finding sexual partners. Moreover, using new programs such as BlackBerry Chat and ToGo that use social network interfaces on cell phones are on the rise.

A friend residing here in Kano said he wants to travel to Zaria, that if I have any numbers to give to him that I should help him. So I now gave him the numbers, and I called the people over there that I have given their number to a friend who is coming to Zaria, that they should accept him, he is good. So that was what happened. (Kano interview respondent)

You call the person on the phone and he will confirm where you got his number from so that it won't be like you want to wear him kitto [embarrass or set him up]. If he knows and he is interested, he will continue because they flirt. And for the big spenders, I am not interested whether he is ugly or whatever; my ideology is based on the money. (Lagos interview respondent)

The Internet has also become instrumental in facilitating connections among MSM. Men in Nigeria use several popular international gay chat sites, but even non-gay sites like Facebook were mentioned as useful for meeting new 
partners. Internet use is especially popular among MSM in Lagos, where English language and computer literacy is higher than in Kano. The Internet is used to meet paying Nigerian sex partners, but is particularly useful for connecting with foreign men:

On [one gay site] for example, there's a forum called Traveller's Forum for travelling, and you click there and you see people who will be travelling to Nigeria in a month or two months time. And you either contact them and ask if you two could meet, or they even get in contact with you after reading through your profile, that they will be coming to Nigeria. So I begin to ask, 'What are you coming for?' I have met a lot of people who are deeply responsible, some are highly placed government officials. (Lagos interview respondent)

\section{G. Negotiating transactions}

Men who transact sex deploy different strategies when negotiating with their partners. Some insisted that it was important for the partners to bargain the terms of the rendezvous in advance to avoid any disagreement. Men in Lagos seem to be more likely than men in Kano to take this direct approach:

Before you go down [to meet a client], negotiate properly. Like a guy at Ajah asked how much my bill was and I was like 15,000 naira. He was like, 'wow!' I said 'yeah, quality treatment', because in my mind, I am not in Lagos to count the bridges for now. I could do that later. [Laughs] But he brought it down to 5,000 , so I said, 'No wahala, at all at all, na him bad pass', so I just enjoyed myself and had fun. (Lagos focus group respondent)

I go straight to the point by asking 'What do you want?' If it's sex, we're transacting how I am going to be paid straightaway. (Lagos interview respondent)

Before you begin to do anything, you have to bargain the price. If it's too much, then the guy will come down a little bit. You have to settle on the price. Also you have to give him transport money on top of whatever you are going to pay him. (Kano interview respondent) 
Other men prefer to avoid advance discussions of money changing hands with their partners, because it is seen as drawing too much attention to the fact that the sexual encounter is ultimately predicated on payment. Such men tend to assume that clients should just know that they expected to be paid and will act accordingly:

I don't negotiate because they will view you as a sex worker, so I usually use my appearance to charm you and get what I want. You just have to pay me well. (Lagos focus group respondent)

I usually tell them I don't pay or bargain for sex. If you don't ask me, I'll give above your expectations. (Lagos interview respondent)

When we finish playing I will not tell him to give me anything. As a matured person, he himself will know what to do. Maybe when he is going, he will just give me anything he likes, and I will not say no. (Kano interview respondent)

We don't bargain. Rather, you should know that the person is financially buoyant before you are coming to visit him. But he himself should know what the game is all about, you understand? So we don't bargain on issues, but the problem is that after doing it you have to give us a reasonable amount of money which will transport us to go home, and we will still have our reserves. (Kano interview respondent)

A common euphemism used in transactional sex is 'transport money'. Rather than openly discussing paying for sex, it is often presumed that older partners will cover the transport costs of their younger sex partners-and further expected that this transport money will be over and above what was actually spent on transportation. This allows for money to exchange hands without directly addressing the fact that it is sex that's being transacted:

Excluding five percent of [MSM] who can ask for the money to be paid for services, the remaining of us hide under the guise of transport or cab money. (Lagos focus group respondent) 
I have always been given money, though I don't see that as you paying me for sex because I won't be hoping for it. Though if I am financially down, I will tell my partner I don't have money for transportation. (Lagos interview respondent)

Transport money is compulsory. It may be 800 to 1000 naira. That is my lowest price for transport money, because I am going to spend 100 or 200 naira for transport and I am going to buy recharge card of 500 naira. But if he is an old man, he has to give me 2,000 to 3,000 naira before I can have sex with him. (Kano interview respondent)

Not all sexual transactions are made for cash; many respondents said that older sex partners give their younger partners gifts or favours. Clothes and shoes, recharge cards, cell phones, sports equipment, and perfumes as popular items:

If you frequently give him gifts, whenever you want to have sex with him he won't deny you, because he knows you shower him with gifts. (Kano focus group respondent)

When the eid festival comes around and a boy wants to ride a horse but doesn't have money to hire the horse, you can give him give him the horse to ride and easily fuck him in exchange. (Kano focus group respondent)

Offers of employment from more established sexual partners and other forms of help are also commonly made in exchange for sex:

There are those that will say, 'I will have sex with you once, and then you'll bring me other boys. I will find you a good job since I know people. You'll be making money more than what I would be giving you for sex.' If you can find that kind of person, it's better, because you could get a good paying job. It's even better than if they would be giving you 100,000 for sex. There are a lot of guys I've seen secure a good job through sex. Some of them made a lot of money. (Kano focus group respondent) 
It is through a contact [that I got a job]. He enjoyed the way I fuck him, and he asked what I am doing and I say, 'I am still in school, university', and he said when I am through, I should let him know, that he will get me a job. So I started working there, and even though when I was working there I still go for runs $\mathrm{o}$, and he didn't know. (Lagos interview respondent)

Transactional sex relationships are also often predicated on the expectation of longer-term assistance. As such, having several older, financially secure sex partners becomes a strategy to mitigate against future insecurities:

There are those that will never bargain with you, because they would be ashamed of doing so. But one day they may have a problem, and they will be thinking of you as someone who could help. Then whenever the boy has problem you must be of assistance to him. Let us assume it is you who fuck a boy and he does not ask you for anything. Then maybe one day you meet him on the road and giving him something for a transport fare, 'Take this for your bike to go home.' Or I may come to you one day and tell you, 'I have such-andsuch problem, please help me with this-and-that.' (Kano focus group respondent)

I could be very sympathetic about issues some people face. And perhaps I am meeting somebody on a date, and afterwards we would have sex, and he kept on and on about telling me his problems. And after having sex, I say, 'Please keep five thousand naira so it could help you fix some of what you're facing.' I mean, this is not paying for sex, but being sympathetic to the issues faced and trying to give support - whether or not this situation [he] put forward is true. (Lagos interview respondent)

Men in such longer-term transactional relationships might not have to negotiate, because over time norms and expectations surrounding payment become established:

There is this regular client and we both know it's always 4,000 naira. [Interviewer: Has he never fallen short?] Yes, he has on a few occasions. But we just see it as normal and just go on since it's not a frequent thing, and because he is a regular. (Lagos interview respondent) 
Prices vary depending on the arrangement between the worker and client. That said, different sexual acts are generally considered worthy of higher pay than others. Being unwilling to perform certain acts may result in reduced benefits. "Romancing" (kissing, mutual masturbation, and oral sex) and thigh sex are not expected to garner profits to the same extent as anal sex. Moreover, being the receptive partner rather than the insertive partner in anal sex is expected to yield greater money or benefits, due to the potential for pain and physical harm:

If you have thigh sex with someone, it's ok to give him whatever you can give him. But if you have anal sex with someone then it's more expensive. (Kano focus group respondent)

I don't kiss or suck dick so I tell anyone from the beginning. And some of them get tired of me, that I used to complain a lot, so he will feel bad and may not give me plenty money. Like where he would have given me 10,000 naira, he will say I should manage 2,000 naira. (Lagos interview respondent)

Several respondents insisted that they are not willing to have anal sex without a condom for any price. However, some also stated that clients sometimes attempt to have condom-less sex in exchange for higher payment.

Some people will even want to pay more [for sex without condom], but I just can't risk my life. (Lagos focus group respondent)

Even if the person wants to pay me more, I don't care. I always use condoms. (Lagos interview respondent)

At first I didn't use to use condoms. But when I was oriented [educated], I started. Especially like two years ago, when I was first tested for HIV in relation to this MSM thing somewhere in Surulere. So it was after. Since then I have been very careful-even when people say, 'I will pay more if you have sex with me without condom.' (Lagos interview respondent)

I don't want to get myself into trouble. Disease is now common, it's everywhere, and you can never tell who has it. So it's better to always use a 
condom when having sex, no matter how much he is going to give you. (Kano interview respondent)

Intermediaries (i.e. 'agents' or 'pimps') are common in both Lagos and Kano. Such men-who themselves likely engage in transactional sex as workers-keep a group of men "on-call" when others contact them looking for sex. Based on the client's preference, the intermediary will connect him with the type of man he is interested in. The use of intermediaries is especially popular with wealthier, high profile clients:

When I was in school, I started pimping with girls and learnt how they related. I also started out by confirming a guy's interest before asking for my $10 \%$ after any deal went through and if you are not close, I get 20\%. Then I started with guys. You know, you know their specs, like some people have flat rates. They don't do more than 20,000 naira. So, some people give me money for bringing them guys, others don't, but however, I get my money. (Lagos focus group respondent)

There's a friend I have at Ajao [housing estate]. Anytime I get there, I just ask, 'Who is the big guy here?' Then he will say, 'You are broke today, abi?' Then he can call somebody and right there he will introduce me to the guy there. And then if I am down, he will take me with his car out or we just walk along to an eatery. (Lagos interview respondent)

There are people that arrange appointments for other people to meet guys, especially those big men that don't want be seen hanging around our spots. What they will do is to have somebody arrange an appointment for them. They will tell him the kind of guy they prefer, and he will go and look for that type. Those [intermediary] people make money. As a matter of fact, I used to do that too. (Kano interview respondent)

Intermediaries generally expect to accrue a financial reward for their services, generally paid to them by the client but sometimes by the sex worker:

That was even when I realised that the guys who took us to Togo make money from us. So I was like, 'If I could also take guys to Togo, I could make money 
and sustain myself too'. (Lagos interview respondent)

He [your agent] will tell you, 'Be ready, I will take you to someone. When I take you there, he will give you so-and-so amount of money. If he gives you 5000 naira, 2000 is mine. You will take something and he [the client] gives me something.' There a lot of agents in harka. (Kano focus group respondent)

\section{H. Secrecy and social stigma}

The fear of being exposed as a man who has sex with other men-regardless of whether the sex is exchanged for economic benefit-is great for most MSM in Nigeria. While some men said that certain members of their family were aware of their same-sex sexual behaviours and did not sever ties with them, most expressed that exposure would likely cause the dissolution of familial relationships:

My family would feel depressed if they knew [I had sex with men]. They would stop treating me the way they do now. They might even disown me. They would say I would spoil the family's image, or spoil other people's children. People in the area would warn their children to stop talking to you or going on errands for you and things like that. All this would happen because of what you are accused of. I really don't want to be exposed. (Kano interview respondent)

Like in my own family, I am a very secret guy. I hardly disclose some matters but my younger brother knows about it because there was a guy who wanted to come and scandalise me so I had to open up to him. (Lagos focus group respondent)

It will be devastating, honestly. My family could send me packing from the house completely. (Kano focus group respondent)

The threat of legal persecution is another reason that MSM are at great pains to hide their same-sex behaviours:

In Nigeria, they can't come up with laws that will stop same-sex [sex]. When 
such comes up is during elections to tackle opponents. You know like there was a candidate for president that was talking about gays and immediately, a Muslim group on the same TV came up that they won't support any gay oriented-president. (Lagos focus group respondent)

The law is not friendly because something out of law is out of bounds. People are just doing their things in a hidden way. (Lagos focus group respondent)

However the likelihood that one will face legal ramifications for same-sex behaviour is related to socio-economic class. Wealthier men are better able to avoid detection, arrest, and prosecution. Thus for poorer men who sell sex, having well-placed clients who can help in case of legal trouble can be important:

From the Islamic sharia point of view, anybody found guilty of harka will be publically executed. But in reality when you are caught, a very rich man who you do harka with will have to run around to see to it that you are released. This happened to me once. Nobody knew about it except my parents and an elder brother. (Kano focus group respondent)

Association with more effeminate men is seen as a particular risk to one's reputation:

I code their phone numbers and I go to meet the effeminate ones at their houses. I don't allow them come around because people will notice. (Lagos interview respondent)

The majority of people do not want to relate with mekoki, because whenever you are seen with them, people will have the idea automatically that you are doing harka. But for a person who is not meka, you can freely move with him without hesitation. (Kano focus group respondent)

While some respondents have managed to "come out" to certain family members and non-MSM friends about their sexuality or have reached a level of self-acceptance, others have clearly experienced major internalized stigma because of their sexual practices. As one married man in Lagos recalled: 
I thought I was the only one doing it [having sex with men]. I even almost hanged myself. It's God that saved me, because then after I do it, I will sit down and think and ask myself, 'What is wrong with me?' I will determine not to do it, but I will find myself in it the following day, week, and month, doing it again. Then I had to make up my mind to not do it again. So I now came to Lagos. And even after praying, fasting, and doing a lot of things so that God will take me out of this condition, I started browsing the Internet and then I discovered that very many people do it. And since then, I have been doing it with wisdom. (Lagos interview respondent)

\section{Verbal and physical attacks}

Many MSM experience verbal harassment based on others' assumption or knowledge of their sexuality:

People insult us in public. They will call us disgusting and dirty and say we're completely useless. Or they call us transvestites, or when you go somewhere they will say, 'Get up, this person is dirty, he's a transvestite, a homosexual, so let's get up and leave. Don't associate with him.' (Kano interview respondent)

Sometimes verbal insults escalate into physical attacks. Respondents in Lagos more commonly recalled attacks by groups of young men on the street:

Some guys were calling me in a harsh tone so I didn't answer. So getting to my friend I didn't meet him, and then I went the same route back home only for me to hear the guys calling and saying, 'Hey...hey, fucking faggot, homosexual, come here.' I didn't answer, so one of them walked up to me and hit me on my back and then pulled me roughly. I was like, what is this? So I stood and tackled him and said, 'Who the hell are you?' So he hit me and I hit him back. Before you know it, I was surrounded by six guys and beaten blue-black. (Lagos interview respondent)

Before the internet came, around 1995 or 1997, there was a guy I liked who was cute looking. I called him and was rubbing him. He tactically excused himself, and raised an alarm and people came and beat me up. I have been beaten like three times in three different locations. And again, at a cyber cafe, a 
guy was browsing straight and gay sites, so I wrongly thought he was gay. I didn't know that he was sending gay men fraud letters. So I started chatting him up. All of a sudden, he arranged some guys in the cyber centre to come and bug me or disturb my peace-and thank God I had great guts. (Lagos interview respondent)

I was going shopping with a friend at Ikeja once and while he was bitching away chewing gum, some guys called him gay. And can you believe that because I said, 'How e take concain you?' ['How does that concern you?] I was beaten and the police some metres away just ignored us. My friend just stood there with his hand on the waist stomping his feet. (Lagos focus group respondent)

Men with more feminine gender presentations were much more likely to have shared experiences of being verbally insulted or physically attacked than were more stereotypically masculine men:

The public wouldn't like you as appearing girlish. Like when going to field I have heard people say, 'Why that one dey waka like say them dey fuck their yansh?' ('Why does that one walk like someone who takes it in the ass?'), 'I never see man like woman before o', and all that stuffs. I am like, 'Who cares?' The public isn't friendly but try not to be very feminine and be confident. Like we were walking along Bode Thomas one day so the touts were like, 'Who are these guys, who born them, where are they coming from?' I was like, 'Sorry o, baba oko mi ('my husband's father)'. They were like, 'Can't you walk like guys?' I was now like, 'Sorry, we are having leg pains.' [Laughter]. That's how we escape. But it's not good to act girlish. (Lagos focus group respondent)

Many respondents feel that such incidences of violence could not be reported to the police. Rather than protecting them from attacks, many MSM feel that the police harass them, especially in the context of parties:

Police or the hisba raid our parties or gatherings at hotels. Recently at a party organized by a meka the police came with their patrol van and picked up almost everyone. Everyone had to bail themselves instantly or be taken to the police station. If you didn't have the money, the police would call your parents and you 
will be exposed to them, and then bailed expensively. (Kano focus group respondent)

Police came and arrested almost thirty people in Sabon Gari at International Hotel, because they never got permission to hold the party. From the police station they were taken to court and asked to each pay 5,000 naira to bail themselves. If not, they'd be sent to prison. The police came because no one asked them for permission and gave them something [i.e. bribed them]. The hisba, on the other hand, even if they were given money they would still spoil things because they know it's a homosexual party. There's Islamic sharia law in the State. (Kano interview respondent)

Stories of rape or otherwise coerced sex involving male partners were rare among our respondents. However, this may reflect the reluctance of men to admit to such events rather than actual incidence: men who are assaulted may not wish to recall such occurrences because the memory carries a residual emotional pain or because they fear being perceived as weak; men who sexually assault other men are unlikely to recount such attacks because of the inappropriateness of such behaviour.

An older guy with a big dick fucked me. He forced me to have sex with him, so I got hurt. When I saw his dick I knew that was going to hurt me-but he insisted. It took some time to heal. [Interviewer: So you didn't go to the hospital because you were worried about telling them what happened?] Yes, because the doctor would surely have asked how it happened. (Kano interview respondent)

\section{J. Theft and blackmail}

Stories of thefts by sexual partners are quite common. Particularly in Lagos, several sex workers relayed stories about having stolen from their sex partners. Often, this was defended in terms of getting what they were worth out of a client who refused to pay them enough for sexual services:

There was this ECOWAS guy in Abuja. Though we didn't agree to anything, I was like, at least I should be expecting 20k [20,000 naira]. So I spent like two 
weeks [with him] and he was like, 'I would like you to spend another week', but I told him I have stuff to do in Lagos. He was now like, 'Please manage this money for me.' When I counted the money, it was like 10k [10,000 naira] and I was like, 'What? No, o!' I now said, fine, let me stay one more week. I strategized and packed his two laptops and Blackberries in one day before taking a flight back to Lagos. (Lagos focus group respondent)

I use to bring someone around and we had sex in my room. When we finished I went to the bathroom, and before I come out had he put his hand in my pocket and stolen my money. Some of them, if you spend a night with them definitely the following morning they will steal something from the room. Handsets and money are the things that they mostly steal. (Kano interview respondent)

There was this runs [client] at Ajah and I was given 1000 naira—for what now?! So I now picked his Blackberry. (Lagos focus group respondent)

It has a lot to do with unemployment. When a person has sex for money but doesn't get paid and then sees something valuable, they most likely will take it—even though it's not good to steal. (Kano interview respondent)

In Kano, where social stigma and sharia legal codes against stealing are much greater, few respondents admitted to having stolen from someone-even though there is a general perception that theft is high. Incidents of theft by male sexual partners are unlikely to be reported to police, since doing so risks selfdisclosure of same-sex sex:

[Theft] is common in Lagos because if you report to the police, the police will make more money. You don't wanna go to jail for 14 years, you don't wanna get your family or people at your workplace to know your sexual status. Because it's more like a weapon used against you, because these guys that get stolen from are usually very discreet and top guys in the society. So they just move on. (Lagos interview respondent)

I love married men because they are matured. They are very good to handle and they are very scared of knock-outs. They comply well and have many things to protect. They pay you just as you bargained. (Lagos focus group respondent) 
Blackmail is also a strategy that sex workers use to increase the benefits they accrue from clients. Since most men greatly fear that their same-sex sexual behaviours will be exposed, they often have little choice but to pay to protect their families, neighbours, or employers from being alerted:

I was with a big shot and I asked for payment from fucking me. And he was like, he paid for my transportation and hotel. I threatened to blackmail him, and it worked. In fact, it works for my big clients, especially when I know where they work and they don't want to drop money. (Lagos interview respondent)

A friend of mine in the bank invited this notorious (gay) guy, and after the show [i.e., sex] demanded for 500 dollars. So because it wasn't agreed upon, the guy couldn't give so the guy picked his laptop, wristwatch and other things. And this my friend could not report to the police or do anything. But he learned to be more careful. (Lagos interview respondent)

There was this guy that we had sex, and after he left I didn't see the camera someone sent to me from Germany. When I called, he said the camera was with him and there was nothing I could do, that if I try to push it further he would tell everyone what we had been doing. (Lagos interview respondent)

In terms of extortion, say when I meet this guy and we dated and had sex, and then he starts threatening that he'll report me to the police or tell people at work because I can't give what he is asking. At that point, I don't even want to go to the police given that we had sex. I had committed sodomy, which is an offence. So what case will I present before the police? (Lagos interview respondent)

\section{K. Alcohol and other drug use}

In Kano, sharia law and Muslim social norms tend to curtail alcohol consumption. But in Lagos, alcohol is readily available in many of the locations where men meet for transactional sex. Being bought drinks by a client before having sex is sometimes seen as part of the bargain: 
It's just like we have drinks from the bars or joints and then we go straight to have sex because nothing else is in their minds. But talking about relationships, they don't believe it, except the rich guys who talk more about relationship. [Interviewer: Do you always expect anything from them? Yes, I always expect drinks and cash. (Lagos interview respondent)

Some men say that being high on alcohol made their sexual encounters more fun, or makes it easier for them to withstand the possible pain of being anally penetrated:

I love being high [on alcohol] before any sexual intercourse. It makes me enjoy sex. Though it's not all the time I drink I have the urge. Though when I have the urge [for sex], I always want to drink because it makes me free and loose. (Lagos interview respondent)

I take [alcohol] forty-five minutes before sex, because it makes me loose and high. I started from secondary school at a parlour party and really, I am always performing more than normal when I take a lot of alcohol. (Lagos interview respondent)

I used to smoke, but I stopped. But alcohol still works for me any time before sex, because it makes my spirit high and I won't feel the pain. (Lagos interview respondent)

When I want to really do it, say for the money, I take alcohol because I know I need to deliver. (Lagos interview respondent)

Some men were aware that using alcohol was likely to change their behaviours and make them more likely to do things they might not otherwise do:

I enjoy Heineken and wine and it makes me loose, especially when I am drunk on say three bottles - though I try to be in the midst of my friends, because the smallest person can have me at that time. (Lagos interview respondent)

For the great majority of men who do sex work, it does not appear that drug dependency is a motivating factor. None of our respondents said that they sold sex to get money for drugs. However, it may be a reason for some:

I feel the drug thing cannot be associated with sexual behaviour. You do drugs or you don't do drugs; you may be a sex worker. I don't see any great influence of drugs. (Lagos interview respondent) 
Some have sex for alcohol because they have no dignity. And some of them are drug abusers and will have sex with anyone for some drugs and will be happy about it. (Kano interview respondent)

\section{Sexual relationships with women}

Throughout Nigeria, heterosexual marriage is expected of virtually all men and women, and is a main marker of social adulthood. The age at which men are expected to marry depends on a variety of factors. For instance, urban men generally marry later than rural men, and men with more education generally marry later than those with less. But sooner or later, most MSM in Nigeria have sexual relationships with and marry women.

The reasons that MSM in Kano and Lagos gave for being married or planning to marry were various. Some men considered themselves to be "naturally" bisexual, attracted to both men and women:

I see myself as a bisexual and my current partner is also bisexual. I feel comfortable with it that I can sleep with both a man and woman because I have feelings for both. Some of my gay friends also know I have sex with women though I don't know if my straight guys know. (Lagos interview respondent)

I want to marry when I graduate [from university], though I am more of bisexual. I enjoy guys more, but I am keeping a girlfriend to fulfil all righteousness - though I will still be doing my things [with men] by the side. (Lagos interview respondent)

Others indicated that their main reason for wanting to marry was to have children:

Everyone wants to have children for the sake of leaving a legacy. When you have children, they will pray for you even after your death. Secondly, if you die without leaving any children, I think you won't be remembered at all. And whatever good they do, it is you who will be remembered. (Kano interview respondent) 
Still others feel little intrinsic desire to partner with and marry women, but face intense family and social pressures to do so. Such men seem resigned to the fact that they would end up married to women:

I will still get married, though deep down in my heart I want to marry a man. But pressure from my mum will have to make me get married. (Lagos interview respondent)

It's because of the kinds of boys that come to my place that spurred my parents into making me get married. And I hide under the pretext of marriage to continue having sex with guys. (Kano focus group respondent)

You know in Nigeria, there are no full-blown gay men. They must get married, even if they don't like their wives. (Lagos interview respondent)

While some MSM aspire to stop having sex with other men upon getting married, many continue to have same-sex encounters. But because such same-sex extramarital relationships would constitute a serious threat to most marriages, men are often at great pains to keep them hidden from wives and girlfriends:

I hide it [sex with other men] from her [my wife] by not taking guys to my house to have sex with them. Secondly, I don't look like a person that will have sex with other men; I look responsible enough. So if she was going to get suspicious, she would probably think I was having an affair with other women. (Kano interview respondent)

Most times, I will be in my house with her [my girlfriend]. My clients may call me on phone or they may send me texts. She will be trying to read the things to know the content of the text, but I may delete the text. I will hide it from her, I may tell her that am travelling home but she will not know that am going to see my clients. (Kano interview respondent)

If my wife knew, she would not like it at all. I would say it's not a good thing when it comes to Muslims. I'm not sure about Christians, whether it's ok or not in their religion. But if it's a Muslim I would say it was a bad thing, and if a 
person's wife found out, she would probably leave and ask for a divorce. So a person should be very careful. If you have a family, he should never let them find out what he does, because that would be really bad. (Kano interview respondent)

A minority of married men believed or knew that their wives were aware of their same-sex behaviours. In such cases there was a tacit, if grudging, acceptance on the part of the wives:

There's no way you could be living with someone in a house and the person won't discover your little secrets, so I had to tell her [my wife] before she hears it from others. It wasn't easy because she didn't swallow it [accept it], but I told her it won't stop me from performing my roles as a husband. She was crying, but I told her, 'As humans, we all have our weak points'. Like you have some men who could be drunkards or sleep with women and doing it without their wife's knowledge. So that I let her know doesn't make her accept wholeheartedly, so I myself try to caution myself and reduce my excesses. (Lagos interview respondent)

There was a time I had this guy I was so much in love with that I even brought him home and introduced to my wife as a fellow colleague. My wife started suspecting that I show him a lot of care and attention, more than her. So she had to tell me the boy must stop coming to the house if I don't want problem or the marriage to scatter [end]. So I had to use my discretion and take control of the situation. (Lagos interview respondent)

While some men said that they aspired to stop having sex with other men after marriage, many furthermore said that in reality this was difficult to do:

This is Nigeria, so you know the policies that guide us. At a time, they will expect you to get married and if you don't, they will start getting suspicious of you and thinking negative things, that maybe you are homosexual or a ritualist. [Interviewer: Do you think after getting married you will have sex with males?] Yes, because the feelings never dies. The feeling runs through you. What you have been used to, you can't dodge it. (Lagos interview respondent) All of them [my clients] - I cannot say 'few' —all of them are married men. But come. I used to wonder: they are married people, but they leave their wife and are still coming to you? [...] I will tell them that 'If I were you people, as far as I 
get married, I would forget about men and face my wife.' They tell me that, 'No, that I cannot do it', that I should try it and see whether I will face my woman. (Kano interview respondent)

In the course of their lives, the vast majority of Nigerian MSM are thus functionally bisexual, having sex with both women and other men. MSM in Nigeria do not therefore constitute a closed sexual community, but rather are sexually integrated into the general population.

\section{HIV and AIDS and other Sexually Transmitted Infections (STIs)}

All of our respondents were aware of the existence of HIV/AIDS and other STIs. However, awareness of the documented higher prevalence of HIV among MSM relative to the general population in Nigeria, and of the higher risks of infection associated with anal sex, were uneven. Knowledge of effective prevention and treatment strategies for HIV and other STIs was high among some respondents, yet many others expressed false beliefs-for instance, about the ability to detect a STI in a sexual partner:

It's not good to put the dick in the mouth immediately, because for instance, I learned some time ago how to test if a man has gonorrhoea: if a guy's dick is rising, play with the tip and squeeze it gently, continuously. Don't put in your mouth immediately. If the person shows pain when you squeeze the tip, the person is infected with a STI. (Lagos interview respondent)

There are some people, by being there you will know they take good care of themselves, so no need to use condom when having sex with them. There are also some people, if you see them you know definitely you have to protect yourself with a condom. I will be able to tell if someone is not healthy. (Kano interview respondent)

Sometimes by looking at you I can tell if you are healthy or not. My body will tell me if this man deserves sex without condom. That is how I choose my sex partners. (Kano interview respondent)

A few respondents expressed the belief that antibiotics taken as either a pre- or 
post-exposure prophylaxis would lessen the likelihood of becoming infected with HIV:

[Interviewer: Do you think you are risk of contracting HIV/AIDs or any other disease?] Respondent: Well, I do protect myself-I take antibacterial drugs. (Kano interview respondent)

The most widespread and arguably the most dangerous false belief we encountered among our respondents was that men were unable or unlikely to sexually infect each other with HIV. In Kano, where there has been virtually no HIV prevention tailored to MSM, the belief that sex between men carried no risk of HIV transmission (or a small risk relative to heterosexual sex) was particularly pervasive:

If a person has to have sex, then it's better to have it with a man, because it's easier to catch an infection from women. (Kano interview respondent)

I think female prostitutes are infected more. A person who has sex with women is more likely to be infected, because gay people don't catch AIDS that much. (Kano interview respondent)

People who only sleep with women are more at risk of getting infected than those who sleep with men. This is my point of view. That is the way I see it. People who sleep with women only are more infected; they come in contact with diseases like gonorrhoea more often, because it's easier to catch them from women. [...] For instance, if two men have sex and the one on top is negative, if he fucks the positive person he won't get infected, as long as there is no blood in there. He is safe as long as he does not come in contact with any blood. (Kano interview respondent)

It is from a woman that I think you can contact it [HIV]. I don't believe it can be contacted from man. (Kano interview respondent)

In Lagos, largely due to campaigns by local and international NGOs to address the sexual health of MSM, in recent years there has been greater awareness among some of the increased risk of HIV infection from anal sex: 
People [MSM] felt that [anal sex] was the safest, that you don't stand a chance of getting HIV. But with the NGOs coming who work with gay people, it's now known that with having anal sex, it is eight times more at risk. [...] The belief of people [from] two years ago [to] now has really improved. (Lagos interview respondent)

Infection with STIs among MSM — especially HIV infection—remains highly stigmatizing. Sexual partners are thus unlikely to discuss HIV status out because of fear of rejection, and also out of concern that the news will spread to the wider community of MSM:

Due to the fact that there is a high level of stigma among the MSMs, people are not really free to express their health status to fellow MSMs because they feel they will be judged. [...] You know, news spreads very fast—and if you tell one person, it spreads to more people than you can imagine in a very short while. (Lagos focus group respondent)

There was a time I had a group of friends and I had gonorrhoea and I tell them everything because we do everything together. I was shy but was looking for a solution. Before I got home, the person I was supposed to go meet called to ask if I truly had gonorrhoea- and he wasn't there when I was discussing it with my friends. With that, I didn't need to be told not to tell anyone whenever I had challenges, especially health related. (Lagos focus group respondent)

[Interviewer: Would you have sex with a partner who is HIV positive?] No, I will not do it if he is positive. I will not even sit close to him. [Interviewer: Why?] I know you can't get it by just sitting with him, but I would not do it. (Kano interview respondent)

The men in our study expressed ambivalence about using condoms. Some said that they always used condoms; some said that they only used them with certain partners, while others said that they rarely or never used them. In general, reported condom use was lower among men in Kano than in Lagos. As one respondent explained, procuring condoms from a pharmacy could be stigmatizing in and of itself: 
Sometimes I feel too embarrassed to buy condoms or lubricants for condoms. Because I am not the type of person who should be buying condoms, that's what they will think. I look too respectable, and I am a married man, so I shouldn't need condoms in the first place. The majority of people who use condoms commit adultery or have sex before marriage, and $80 \%$ of married people don't use condoms anyway. (Kano interview respondent)

Several men said that their condom use with male partners depended on how well they knew or felt they could trust their partner, or with the sexual role they would play in anal sex:

If you have a condom, you use it—but it depends if you don't have a condom. And, it depends on the person. Some people you trust enough to have sex [without a condom], and other people, you will need to put a condom on. But you have people you trust and can have sex with them even without a condom. (Kano interview respondent)

It's not everybody that you see that will like condoms, and it's not everybody I have sex with. If I don't trust you, I use a condom. But if I trust you, I don't use a condom. Like the people that do it [sex] too much, I don't go near them. (Kano interview respondent)

My friend that introduced me to that stuff [gay sex], when we are meeting ourselves [having sex], we don't use condoms. But when it is other people, we use condoms when we are going bottom. But if we are just to play top, we don't use condoms. (Kano interview respondent)

[Interviewer: Do you use condoms?] Yes, very regularly. In fact, more often than not. (Lagos interview respondent)

Other men said that they rarely, if ever, used condoms with male partners:

I don't normally use condoms, but as I am moving with different guys I need to protect my health and start using. (Lagos interview respondent)

[Interviewer: Do you ever use condoms?] No, no. That is why I tell you that 
boys I introduce [to sex] cannot go aimlessly. So na only him I dey penetrate [that's the only type I penetrate]. [Interviewer: When you have sex with them, do you release inside?] Yes, and they enjoy am [it]. Some will even say, make you hold their prick 'til they release. [Interviewer: So how do you protect yourself from HIV?] That is what I am telling you. That if I no sabi [don't know] you well-well [very well] and know your health beyond reasonable doubts, I cannot penetrate you. Not like all these almajiri [beggars] o. He must be neat. (Kano interview respondent)

Especially if the person can go like one hour with me, I will offer myself raw. (Lagos interview respondent)

[MSM] in Kano don't wear condoms at all—except for big people who ask pimps to bring them boys from different cities like Abuja. When they have sex with them [i.e. boys from cities like Abuja] they wear condoms because they don't trust them. But usually they don't wear condoms. They only wear them when they're having sex with women. [Interviewer: Why don't they use condoms?] Some people think it hurts when they use condoms, and some people don't enjoy using condoms. Some women say condoms hurt, so you shouldn't use one. Some men say they won't do it with a condom because they don't enjoy it. Some say you have to use one because they're scared of getting infected, but most have anal sex and have it just like that [without condoms]. (Kano interview respondent)

To protect myself from diseases whenever I've had sex I will make sure I wash with Detol. I also don't have sex with dirty people. I always look for nice, handsome guys. [Interviewer: Do you use condoms?] No, I never use condoms. [Interviewer: Why not?] Because I don't know them and I'm not used to them. (Kano interview respondent)

One more effective strategy adopted by some men is to avoid anal sex in favour of sexual practices that carry dramatically less risk of disease transmission. A notable example, more commonly discussed in Kano than in Lagos, is interfemoral sex (more commonly known in among MSM in Nigeria as 'lap sex', or kauye in Hausa): 
I prefer sex between the thighs. I don't like anal sex because of infection. (Kano interview respondent)

Despite the heavy burden of HIV infection in Nigeria, epidemiological and social research on HIV among MSM in Nigeria is still rare. There have been few studies of HIV prevalence among MSM, and no studies comparing rates of infection in MSM who engage in transactional sex and those who don't. We contend however that MSM who have sex in exchange for money or other gifts are at an especially high risk of HIV infection. Such men are exposed to greater risk because they are likely to have sex with multiple partners from the high HIV prevalence population of urban MSM, and moreover because they may be less likely to negotiate harm reduction practices such as condom use with their paying partners. Furthermore, our research indicated that many men were unaware of the higher risk of sexual transmission from unprotected anal sex, particularly in Kano.

\section{N. Access to sexual health information and services}

MSM are generally uncomfortable discussing their sexual health with mainstream medical providers in Nigeria due to the fact that same-sex sex is both criminalized and socially stigmatized. This led several of our informants to either avoid health services when they were needed, or to not disclose their sexual health problems in clinical settings-particularly in the case of anal health problems.

Honestly, the doctor asked [how I got haemorrhoids], but I just told him that I was having stomach pain, that's all. But he knew [the real reason], and just shook his head and wrote me a prescription. It was when I went to the pharmacy that the pharmacist looked at me and said, 'May Allah have mercy upon you'. I think he somehow knew how I got haemorrhoids. (Kano interview respondent)

There's no reason to say anything [to health workers], because how are you sure your confidentiality is secret? (Lagos focus group respondent)

No, I can't just tell anybody. I have to be able to trust the doctor, though a 
doctor should know what to do. And again, if a doctor doesn't ask, why tell? (Lagos interview respondent)

For some, the lack of trusted clinical services led to self-treatment strategies:

Last time I experienced pains in my penis, I know that that one is gonorrhoea. So I went to the market and bought the injections and gave it to myself three times. (Kano interview respondent)

The generally hostile environment for MSM across Nigeria illustrates the need for expanding targeted health information and services for this population.

[Religious leaders] look at the practice and act [of homosexuality] as wrong, but I tell people that if you neglect the gay or MSM community in Nigeria, you'll neglect like ten percent of the population-like 15 million people. And if this figure had HIV, you don't want to imagine. (Lagos interview respondent)

Some noted the unavailability of condom-compatible lubricants as a barrier to condom use:

Some said with women [sexual partners] they are free [to use condoms] because it's the woman with the liquid in them; it's like lubricant. But with men, when they wear the condom, they still have to look for lubricant. (Kano interview respondent)

In Lagos, a few NGOs have begun offering culturally sensitive sexual health information and services for MSM in recent years. While these programs likely only reach a small fraction of the men who would benefit from them (and must operate in a climate that is generally hostile to MSM), several respondents noted that these programs had changed their health-seeking and sexual behaviours:

It must be a doctor that is friendly and professional. Like there was one asking what was wrong with me in a probing manner and looking at me funnily, so I only will be going to that Population Council health centre now. (Lagos interview respondent) 
I didn't use condoms before the coming of your organisation, but with the information I have been getting, I use condoms all the time now. And I also use lubricants because Vaseline is not too good for my skin. (Lagos interview respondent)

In Kano, there have been virtually no formal efforts to educate men about male-male sexual health, and health services for MSM are nascent at best. Thus, in Kano the ability to access non-stigmatizing sexual health services for MSM depends largely on knowing a doctor who himself has sex with other men. Several respondents in Kano asked the interviewers where they could access services.

A lot of gay men are too embarrassed to go to the hospital. They need an association that will help them by taking them to the hospital. (Kano interview respondent)

You need to be an insider and you need to trust them, be open to them so that they will trust you too. You also need to be patient and be able to listen to them anytime because if they believe in you, they can talk to you anytime. And you know, they are marginalised in their community, so you have to move them outside their community to somewhere safe and quiet places. You know, like you can't just bring them into a primary school where people will be saying, 'Who are these people gathering?' (Kano interview respondent) 


\section{IMPLICATIONS AND COMMENDATIONS}

\section{A. Health education}

The results of this study highlight the need to get basic information about sexual health to MSM and to especially vulnerable subgroups of men engaged in transactional sex in Nigeria. The federal and state governments, local and international NGOs, and communities of MSM all have important and complementary roles to play in improving the health and safety of MSM.

Several advances in this regard have been made in recent years. Local LGBT groups including The Initiative for Equal Rights (TIER), The Initiative for Improved Male Health (IMH-I) and The International Centre on Advocacy for the Rights to Health (ICARH) and international NGOs including Population Council, Family Health International, Institute of Human Virology-Nigeria, and Heartland Alliance have provided Nigerian MSM with targeted health education messages through published materials, special events, and peer education. A Peer Education manual developed by the National Agency for the Control of AIDS is also a step in the right direction. Yet, the attention paid to the public health crisis among MSM in Nigeria by state and federal governments and by civil society organizations has thus far been grossly incommensurate with the scope of the problem.

It is important to recognize when planning educational programmes that only a small percentage of MSM in Nigeria are "out" and easily reachable through conventional campaigns. Older men, married men, and those who do not consider themselves gay are much less likely to be reached by traditional approaches to public health messaging. The cultural sensitivity of conducting mass campaigns targeting MSM and the likelihood that such efforts could result in a homophobic backlash are another programmatic consideration. Furthermore, many MSM in linguistically pluralistic Nigeria are not literate in English, and may not be literate in any language. 
Peer education should therefore be a main strategy for getting MSM, and subsets such as those who engage in transactional sex, the health information they need. The benefits of peer education are at least twofold: first, given the secrecy and stigma surrounding same-sex sexuality in Nigeria, MSM are in the best position to reach out to fellow MSM-especially those who are unlikely to be "found" by government agencies and NGOs. Second, a peer education model recognizes that with proper institutional support, MSM can be empowered to effectively address the unmet needs that members of the community consider the most pressing.

MSM should be involved in all aspects of planning, message development, and campaign roll-out for education campaigns to be effective-rather than used as "implementing partners" when programmes have already been developed. A peer education model does not relieve the federal and state governments of their duty to protect the public health by shifting the programmatic onus to marginalized and under-resourced groups of MSM. Rather, it challenges the government and NGOs to forge meaningful alliances with MSM and recognizes that programmes that do not incorporate MSM in all levels of decision-making are unlikely to succeed in the long term.

Furthermore, we advocate for the mainstreaming of education about MSM's sexual health and vulnerabilities in the training of health care professionals throughout Nigeria. Recognizing that social attitudes towards marginalized groups are often slow to change and that such efforts may be met with a certain level of resistance, we propose that medical and public health professional training include information on best practices for working with MSM clients and the particular vulnerabilities that such men face.

\section{B. Health care services}

While health education is a laudable and necessary first step, on its own it is not enough. In addition to having basic knowledge about HIV/AIDS and other STIs, MSM in Nigeria need access to a range of services and products to protect themselves from health problems, and to treat existing problems in a non-judgmental, hassle-free environment. 
Our study illustrates that MSM are unlikely to reveal their sexual behaviours to most medical practitioners due to stigma and the perception of negative social consequences. It is also unlikely that, given prevailing attitudes towards homosexuality, most Nigerian medical practitioners will feel comfortable working with this population at this time. We therefore advocate for the expansion of MSM-friendly clinics, where staff have been trained in both the medical specificities and social sensitivities of working with this population.

MSM-friendly health services have been established at pre-existing private clinics recently in Lagos (e.g. Population Council's Men's Health Network; and services provided by the LGBT groups ); information about these services has been disseminated both by the supporting organizations, and informally through social networks of MSM. In Kano MSM-targeted services are still nascent; such services do not exist in the vast majority of Nigeria, even in major urban centres.

Ideally, clinical services should follow a "one-stop shopping" model, with testing and treatment for STIs and HIV, condoms and condom-compatible lubricants, referrals to other clinical services, and MSM-specific health information all readily available. The cost of services is another major factor. Many young MSM engage in transactional sex precisely because they are economically disadvantaged, and are therefore unlikely to be able to afford appropriate healthcare when they need it. Such services should therefore be provided free of cost to maximize uptake. As identity management is a key concern for many MSM, service providers must also be trained in the importance of maintaining strict patient confidentiality, and clinics should be both easily accessible and in an environment where MSM feel safe from exposure.

Federal, state, and local government agencies currently provide no health care services addressing the health needs and vulnerabilities specific to MSM anywhere in Nigeria. These services, in the few places where they exist, have become the providence of a coalition of NGOs with varying levels of funding, effectiveness, and collaboration with local MSM. Without denying the crucial role that NGOs are playing and will continue to play in addressing the needs of MSM, we envision the development of national and state-level government 
commitments. NACA and The Federal Ministry of Health should establish a taskforce on the health of sexual minorities to address the disproportionate burden of HIV/AIDS and other STIs among MSM in Nigeria. Federal and state funding for HIV/AIDS and sexual health services should be allocated to reflect the high burden of disease among MSM-recognizing that tailored service provision for high prevalence groups like MSM will have an impact on the health of the general population.

\section{Policy context of same-sex relations}

Laws criminalizing same-sex sexual activity between consenting adults have been enforced throughout Nigeria since the colonial era, and remain in place today. Chapter 21, Articles 214 and 217 of the Nigerian penal code make homosexuality punishable by imprisonment of up to 14 years throughout the country. Such laws are used to entrap and imprison MSM, and moreover shape society's perception of such men as inherently criminal and immoral. In the context of public health, Nigeria's anti-sodomy laws have constrained the efforts of both government and non-governmental actors to adequately address the AIDS epidemic.

In Kano, as in all the twelve northern states that have adopted sharia criminal codes since 2000, sodomy is punishable by death for married and divorced Muslim men. While it does not appear that capital punishment has ever been carried out for a conviction of sodomy in the north, such laws have set a chilling tone for MSM and those who advocate for their well-being. In Lagos State, recent legislative efforts to make homosexual acts or merely "parading oneself" as a homosexual punishable by 10 years imprisonment have had a similarly chilling effect (Adaramola, 2009).

The criminalization of same-sex behaviour among consenting adults does little or nothing to reduce such behaviours from occurring. Rather, these laws institutionalize homophobia and hamper the development of appropriate sexual health programmes, keeping MSM from accessing information and services. We therefore recommend that Nigeria decriminalize same-sex relations among consenting adults at all levels of the legal system. India's 2009 
decision to decriminalize same-sex sex between consenting adults-supported by a broad coalition of human rights supporters including the National AIDS Control Association of India-is an example of how these discriminatory colonial-era codes can be changed to advance the legal, social, and physical well-being of sexual minorities.

Policy-level interventions like decriminalizing homosexuality and the dramatic scale-up of public health programming for MSM may seem unrealistic, given social attitudes and the slow movement of legislative processes. We nevertheless contend that such interventions are prerequisites to successfully addressing the alarming social and health problems facing MSM in Nigeria — especially young and economically unstable men who sell sex and are therefore at greatest risk for ill health outcomes and discrimination. We envision deepening collaboration between coalitions of local, national and international LGBT advocacy groups, and NGOs who work for sexual health and human rights and evidenced-based public health policies. 


\section{REFERENCES}

Adaramola, Zakariyya. 2009. 10-year jail term for homosexuals. Daily Trust. 30 June. Page 4.

Aina, Tade. 1991. Patterns of Bisexuality in Sub-Saharan Africa. In Bisexuality and HIV/AIDS: A Global Perspective. Edited by R. A. P. Tielman, M. Carballo and A. C. Hendriks. New York: Prometheus Books. Pp. 81-90.

Allman, Dan, et al. 2007. Challenges for the sexual health and social acceptance of men who have sex with men in Nigeria. Culture, Health \& Sexuality 9(2): 152-168.

Arnott, Jayne and Crago, Anna-Louise. 2009. Rights Not Rescue: A report on Female, Male, and Trans Sex Workers' Human Rights in Botswana, Namibia, and South Africa. Open Society Initiative for Southern Africa Sexual Health and Right Project.

http://www.soros.org/initiatives/health/focus/sharp/articles_publications/pub lications/rights_20090626/rightsnotrescue_20090706.pdf

Bernard, H. Russell. 2006. Research Methods in Anthropology: Qualitative and Quantitative Approaches (Fourth Edition). Oxford: AltaMira Press.

Chatterji, Minki, et al. 2004. The factors influencing transactional sex among young men and women in 12 sub-Saharan African countries. The Policy Project.http://www.policyproject.com/pubs/countryreports/Trans_Sex.pdf

Cole, Jennifer. 2009. Love, Money, and Economies of Intimacy in Tamatave, Madagascar. In Love in Africa. Edited by J. Cole and L. Thomas. Chicago: The University of Chicago Press. Pp.109-134.

Epprecht, Mark. 2008. Heterosexual Africa?: The History of an Idea from the Age of Exploration to the Age of AIDS. Athens: Ohio University Press.

Family Health International. 2009. Sexual behavior and characteristics of men who have sex with men: Report of in-depth interviews conducted by Family Health International in Abuja and Lagos, Nigeria. Abuja: FHI. 
Federal Ministry of Health [Nigeria]. 2007 HIV/STI Integrated Biological Behavioural Surveillance Survey.

Gaudio, Rudolf. 2009. Allah Made Us: Sexual Outlaws in an Islamic African City. Malden: Wiley-Blackwell.

Geibel, Scott, et al. 2007. 'Are you on the market?': a capture-recapture enumeration of men who sell sex to men in and around Mombasa, Kenya. AIDS 19;21(10):1349-54.

Geibel Scott, et al. 2008. Factors Associated With Self-Reported Unprotected Anal Sex Among Male Sex Workers in Mombasa, Kenya. Sexual Transmission of Disease 35(8):746-52.

Hunter, Mark. 2002. The Materiality of Everyday Sex: thinking beyond 'prostitution'. African Studies 61(1): 99-120.

Kaufman, Carol E. and Stavrou, Stavros E. 2004 'Bus fare please': the economics of sex and gifts among young people in urban South Africa. Culture, Health \& Sexuality 6 (5): 377-91.

Kleis, Gerald W. and Abdullahi, Salisu A. 1983. Masculine power and gender ambiguity in urban Hausa society. African Urban Studies 16: 39-53.

Masvawure, Tsitsi. 2010. 'I just need to be flashy on campus': female students and transactional sex at a university in Zimbabwe. Culture, Health \& Sexuality $12(8)$ : 857-70.

Murray, Stephen O. and Roscoe, Will. 1998 . Boy-Wives and Female Husbands: Studies in African Homosexualities. 1st edition. New York: St. Martin's Press.

National Agency for the Control of AIDS - Nigeria. 2010 Modes of HIV Transmission in Nigeria. Abuja: NACA. 
Niang, Cheikh I, et al. 2003 'It's raining stones': stigma, violence and HIV vulnerability among men who have sex with men in Dakar, Senegal. Culture, Health, and Sexuality 5: 499-512.

Onyango-Ouma, Washington, et al. 2005. Understanding the HIV/STI risks and prevention needs of men who have sex with men in Nairobi, Kenya. Washington: Population Council.

Pittin, Renne. 2003. Women and Work in Northern Nigeria: Transcending Boundaries. New York: Palgrave MacMillan.

Smith, Daniel J. 2003. Imagining HIV/AIDS: Morality and Perceptions of Personal Risk in Nigeria. Medical Anthropology 22(4): 343 - 372.

Van Griensven, Frits. 2007. Editorial: Men who have sex with men and their HIV epidemics in Africa. AIDS 21(10):1361-1362.

Wojcicki, Janet M. 2002. Commercial Sexwork Or Ukuphanda? Sex-ForMoney Exchange In Soweto And Hammanskrall Area, South Africa. Culture, Medicine and Psychiatry 26:339-370.

Zulu, Eliya M., et al. 2004. Urbanization, poverty and sex: roots of risky sexual behaviors in slum settlements in Nairobi, Kenya. In HIV and AIDS in Africa: Beyond Epidemiology. Edited by E. Kalipeni. Pp. 167-174. Malden: Blackwell Publishing. 


\section{Study Team}

\section{Interviewers}

1. Kayode Gomes

2. Patrick Enweonwu

3. Cheidu Ifankendu

4. Tope Akinwande

5. Samuel Okafor

\section{Mobilizers}

1. Gbemi O.

2. Jumbo D.

3. Taiwo O.

4. Samusudeen D.

\section{Supervisors}

1. Apera Iorwakwagh (Population Council)

2. Olusegun Sangowawa (Population Council)

\section{Research Coordinator}

Jack Ume Tocco (University of Michigan, Ann Arbor, USA.)

\section{Research Assistant}

Denis Akpona (The Initiative for Equal Rights)

\section{Principal Investigators}

DrAndrew Karlyn (Population Council)

Dr Sylvia Adebajo (Population Council)

\section{Editor}

Dr Babatunde Ahonsi (Population Council) 


\section{Population Council}

\section{Nigeria}

16 Mafemi Crescent, Off Solomon Lar Way, Utako District, Abuja, 